- Illustrates that trauma can precipitate gingival recession.

- Highlights the dangers to delicate gingival tissue of certain forms of body art.

- Gives practitioners an excellent example with good photographs with which to demonstrate these problems to patients.

\title{
Gingival recession due to trauma caused by a lower lip stud
}

\author{
J. J. O'Dwyer ${ }^{1}$ and A. Holmes ${ }^{2}$
}

Body piercing seems to be increasing in popularity, with more patients attending for their routine check-up having had a tongue or lip stud placed. Many complications have been documented, some of them, particularly involving tongue piercing, can be life threatening. There appears to be fewer problems associated with lip piercing; however this case study illustrates the damage that a lip stud can cause to previously healthy gingival tissue.

The various forms of body art seem as popular as ever, with the tattoo parlour a common sight on many high streets. These establishments more often than not also carry out body piercing, and the tongue and lower lip appear to be the most common intraoral sites for the placement of jewellery. ${ }^{1}$ Usually steel studs and barbells that can be purchased commercially are used. The individuals that carry out the piercing are unregulated and often self trained and this has raised questions about the cross infection control measures employed. .,3 $^{2,3}$

Several complications associated with intraoral piercing have been reported. Perkins et $a l^{4}$ described a case of Ludwig's angina following piercing of the tongue. Gingival trauma and recession in relation to tongue $^{1}$ and lip studs ${ }^{5}$ have also been described. We discuss the case of a teenager suffering gingival recession after placement of a lower lip stud or labrette.

${ }^{1}$ Specialist Registrar Orthodontic Department Chesterfield and North Derbyshire Royal Hospital, Calow, Chesterfield. Derbyshire S44 5BL. ${ }^{2}$ Consultant Orthodontist, Department of Oral and Maxillofacial Surgery and Orthodontics,

Doncaster Royal Infirmary, Armthorpe Road, Doncaster.

DN2 5LT.

Correspondence to: Mr J. J. O'Dwyer, Chesterfield and

North Derbyshire Royal Hospital

Email:alijod@aol.com

\section{Refereed Paper}

Received 26.07.01; Accepted 26.11.01

$\odot$ British Dental Journal 2002; 192: 615-616

\section{CASE REPORT}

A 16-year-old female patient, with no relevant medical history attended six months after debonding of her upper and lower fixed pre-adjusted edgewise orthodontic appliances, for a routine review of retention. Upper and lower Hawley retainers had been provided at the cessation of active orthodontic treatment, with the patient instructed to wear the upper appliance full time and the lower at night only. These did not impinge on the labial gingivae. The patient had acquired a lower lip stud or labrette some time following her initial review of retention that was carried out at two months debond, and at which the clinical photograph (Fig 1) was obtained. It was noted that the lip stud was not symmetrically placed, being slightly over to the right of the midline (Fig 2).

On examination intra-orally the standard of oral hygiene was good, and the gingivae were generally healthy. There was, however, a localized area of gingival recession labial to the lower right central incisor. No other areas of gingival recession were visible. Surprisingly there appeared to be little gingival inflammation associated with this soft tissue defect. There was a close association between the intra-oral component of the stud and the area of recession.

The patient was not aware of the problem and had no symptoms associated with the 


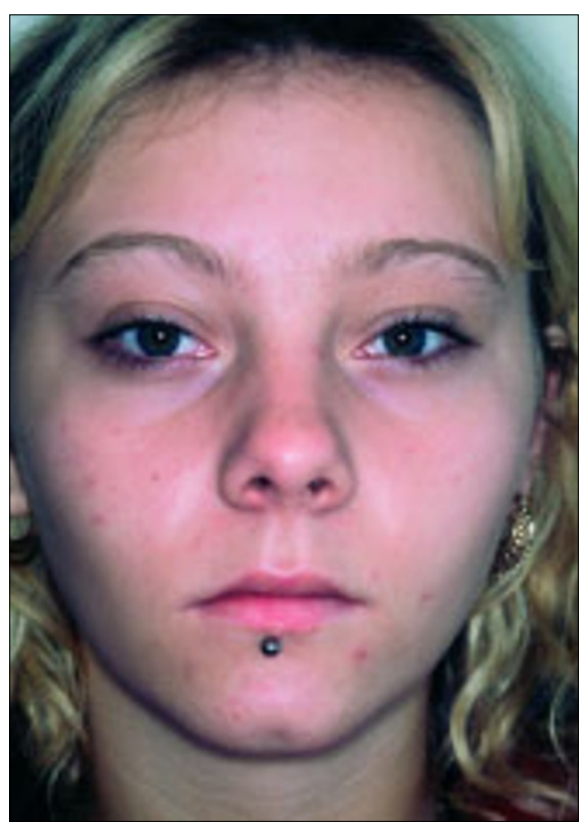

Figure 2. Extra-oral appearance of the lip stud at appointment 6 months after debonding. Note asymmetrical position.

affected area. The probable aetiology was explained to the patient and she was advised to remove the stud.

At the review appointment one year after debonding of the fixed appliances, the lip stud had unfortunately not been removed. The area of gingival recession had not deteriorated further. The patient failed to attend subsequent appointments and further attempts to follow-up this problem have failed.

\section{DISCUSSION}

Fixed orthodontic appliances tend to increase the retention of plaque and food debris on teeth and consequently most patients fitted with fixed appliances will

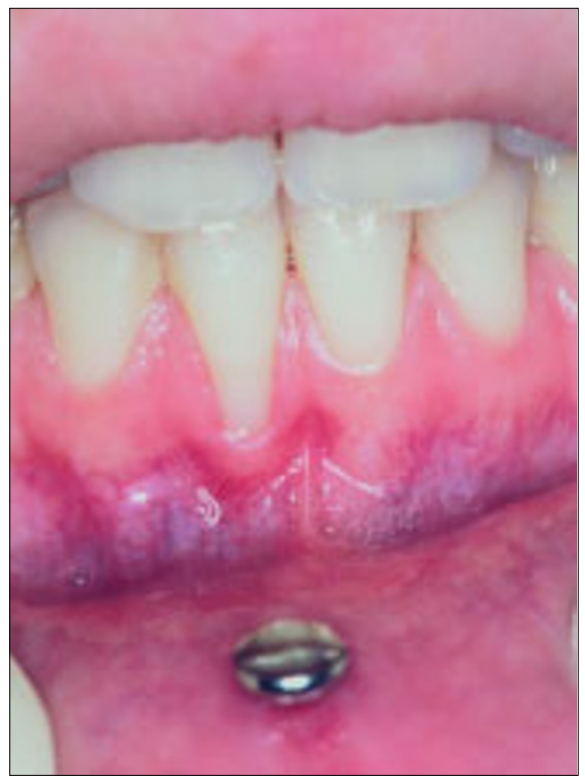

Figure 3. Gingival recession affecting lower right central incisor only. develop gingivitis at some stage during treatment. Despite this, no long-term difference has been reported in periodontal status of patients that have received orthodontic treatment and those that have not. ${ }^{6}$ Certain types of orthodontic treatment, particularly non-extraction therapy, have been associated with proclination of the lower incisors. Excessive lower incisor proclination can lead to gingival recession.

The orthodontic treatment for this patient involved extraction of four premolars, and as the clinical photograph posttreatment (Fig 1) shows no proclination of the lower incisors occurred during treatment. Fig 1 also demonstrates the excellent oral hygiene and gingival health in this patient after debonding. It seems highly unlikely that either of these possible aetiological factors contributed towards the gingival recession seen in this patient.

As can be seen in Fig 3 and Fig 4 the metal stud was retained with a screwed on backing disc. This appeared to be relatively flat with no sharp edges. Due to the asymmetrical placement of the stud, there did seem to be a close relationship of this disc to the gingival margin of the lower right central incisor when the lip was allowed to drop into its natural resting position. It seems most probable that chronic trauma caused by this jewellery led to the gingival recession.

Gingival recession is commonly encountered in clinical practice. It is often a source of anxiety for patients and the exposure of root surface resulting can also lead to symptoms of sensitivity. Trauma, especially that caused by improper tooth brushing, is a well-recognised cause of gingival recession. Treatment usually consists of in the first instance trying to elimi- nate the factors leading to the recession (if they can be ascertained). This will in most cases prevent progression of the recession. Definitive treatment involves surgical repair of the soft tissue defect. The procedures used fall into two groups:

1. Pedicle soft tissue graft procedures eg the laterally repositioned flap and the apically repositioned flap.

2. Free soft tissue graft procedures.

Wennström and Pini Prato $^{7}$ provide good details of the procedures involved with excellent diagrams and clinical photographs. An excellent surgical technique and gentle handling of the soft tissues are prerequisites for success.

This patient was not interested in any treatment as she had no symptoms and had not even noticed that the defect had developed. At the current time we are not aware if the advice to remove the stud was heeded.

Patients with lip studs should be warned of the risk of damage to the periodontal tissues.

Many thanks to the Medical Photography Department at Doncaster Royal Infirmary for the clinical photography.

1 Boardman R, Smith R A. Dental implications of oral piercing. J CalifDent Assoc 1997; 25: 200-207.

2 Price SS, Lewis M W. Body piercing involving oral sites. J Am Dent Assoc 1997; 128: 1017-1020.

3 Kopp W K. Piercing J Am Dent Assoc 1998; 129: 16.

4 Perkins C S, Meisner J, Harrison J M. A complication of tongue piercing. Br Dent J 1997; 182: 147-148.

5 Er N, Özkavak A, Berberoőlu A, Yamalik N. An Unusual Cause of Gingival Recession: Oral Piercing. J Periodonto/ 2000; 71: 1767-1769.

6 Polson A M, Subtelny J D, Meitner SW, Polson A P, Sommers E W, Iker H P, Reed B E. Long-term periodontal status after orthodontic treatment. Am J Orthod Dentofac Orthop 1988; 93: 51-58.

7 Wennström J, Pini Prato G P. Mucoginival Therapy. In Lindhe J, Karring T, Lang N P (ed). Clinical Periodontology and Implant Dentistry.3rd ed. pp550596. Munksgaard, 1998.

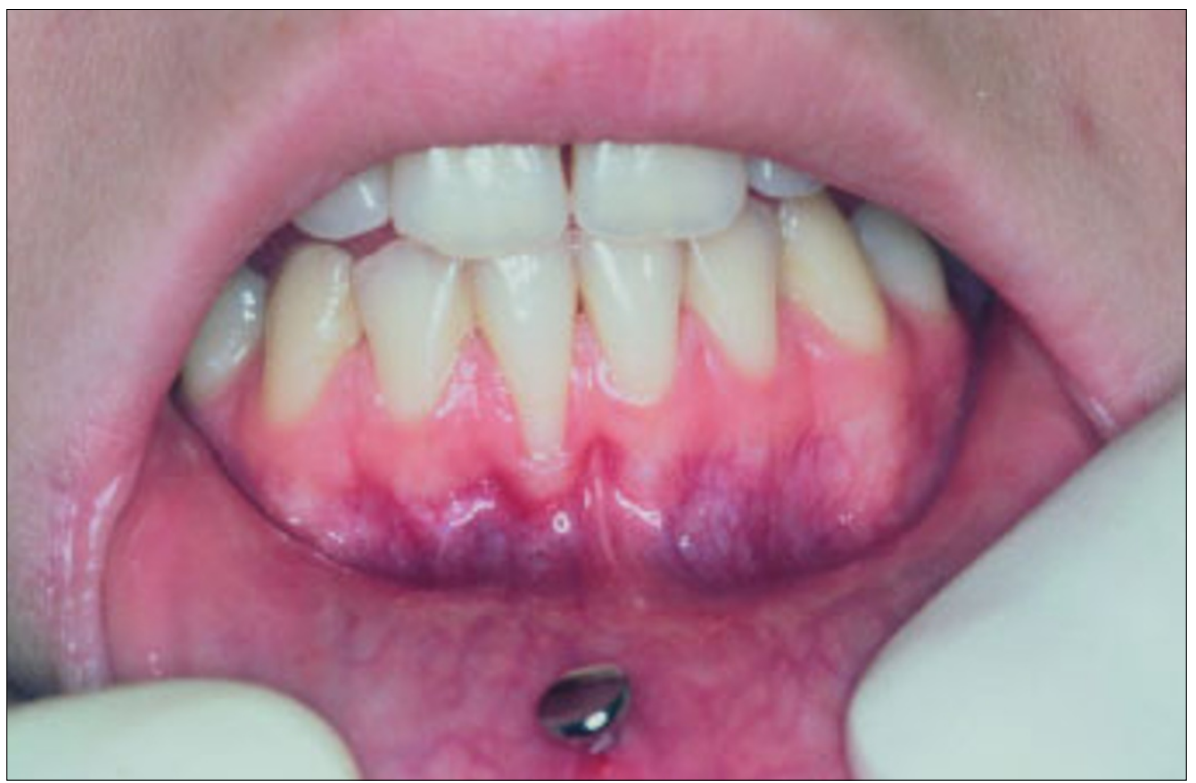

Figure 4. Recession seems to be related to intra-oral component of lip stud. 